\title{
The HNF1 $\alpha$-Regulated LncRNA HNF1 $\alpha$-AS1 Is Involved in the Regulation of Cytochrome P450 Expression in Human Liver Tissues and Huh7 Cells $\mathbf{s}$
}

\author{
Yiting Wang, ${ }^{1}$ Liang Yan, ${ }^{1}$ Jingyang Liu, Shitong Chen, Guangming Liu, Yali Nie, Pei Wang, \\ Weihong Yang, Liming Chen, Xiaobo Zhong, Shengna Han, and Lirong Zhang \\ Department of Pharmacology (Y.W., L.Y., J.L., S.C., G.L., Y.N., P.W., S.H., L.Z.) and Forensic Medicine (W.Y.), School of Basic \\ Medical Sciences, Zhengzhou University, Zhengzhou, Henan, China; Department of Pharmacy, The First Affiliated Hospital of \\ Zhengzhou University, Zhengzhou, Henan, China (L.Y.); and Department of Pharmaceutical Sciences, School of Pharmacy, \\ University of Connecticut, Storrs, Connecticut (L.C., X.Z.)
}

Received August 20, 2018; accepted December 4, 2018

\begin{abstract}
Expression of cytochrome P450s (P450s) is regulated by epigenetic factors, such as DNA methylation, histone modifications, and noncoding RNAs through different mechanisms. Among these factors, long noncoding RNAs (IncRNAs) have been shown to play important roles in the regulation of gene expression; however, little is known about the effects of IncRNAs on the regulation of $\mathrm{P} 450$ expression. The aim of this study was to explore the role of IncRNAs in the regulation of P450 expression by using human liver tissues and hepatoma Huh7 cells. Through IncRNA microarray analysis and quantitative polymerase chain reaction in human liver tissues, we found that the IncRNA hepatocyte nuclear factor 1 alpha antisense 1 (HNF1 $\alpha$-AS1), an antisense RNA of $\mathrm{HNF} 1 \alpha$, is positively correlated with the mRNA expression
\end{abstract}

of CYP2C8, 2C9, 2C19, 2D6, 2E1, and 3A4 as well as pregnane $X$ receptor (PXR) and constitutive androstane receptor (CAR). Gain- and loss-of-function studies in Huh7 cells transfected with small interfering RNAs or overexpression plasmids showed that $\mathrm{HNF} 1 \alpha$ not only regulated the expression of HNF1 $1 \alpha-\mathrm{AS} 1$ and P450s, but also regulated the expression of CAR, PXR, and aryl hydrocarbon receptor (AhR). In turn, HNF1 $\alpha$-AS1 regulated the expression of PXR and most P450s without affecting the expression of HNF1 $\alpha$, AhR, and CAR. Moreover, the rifampicin-induced expression of P450s was also affected by $\mathrm{HNF} 1 \alpha$ and HNF $1 \alpha-\mathrm{AS} 1$. In summary, the results of this study suggested that $\mathrm{HNF} 1 \alpha-\mathrm{AS} 1$ is involved in the HNF1 $\alpha$-mediated regulation of P450s in the liver at both basal and drug-induced levels.

\section{Introduction}

Cytochrome P450 enzymes (P450s) are monooxygenases responsible for the metabolism of most clinically used drugs (Nair et al., 2016). Significant interindividual variability in P450-mediated drug metabolism leads to various responses to drugs in clinical practice (Zanger and Schwab, 2013). Factors contributing to changes in $\mathrm{P} 450$ expression and function account for the interindividual variability in P450-mediated drug metabolism, including genetic, epigenetic, physiologic, pathologic, and environmental factors (Zhou et al., 2009; Zanger et al., 2014; Tracy et al., 2016; Yu et al., 2017). Uncovering the molecular mechanisms in the regulation of $\mathrm{P} 450$ expression

This work was supported by the National Natural Science Foundation of China [Grant 81773815 and U1604163 (L.Z.)] and the US National Institutes of Health National Institute of General Medical Sciences [Grant R01GM118367 (X.Z)].

${ }^{1}$ Y.W. and L.Y. contributed equally to this work.

https://doi.org/10.1124/jpet.118.252940.

S This article has supplemental material available at jpet.aspetjournals.org. would therefore be beneficial to making therapies more effective and drugs safer.

Genetic polymorphism constitutes an important mechanism affecting the expression and functions of P450s but can only explain a proportion (15\%-30\%) of the interindividual differences among global populations (Ingelman-Sundberg et al., 2007; Pinto and Dolan, 2011). Epigenetic mechanisms are also important for the regulation of $\mathrm{P} 450$ expression, including DNA methylation, histone modifications, and noncoding RNAs (Peng and Zhong, 2015; Tang and Chen, 2015). Both DNA methylation and histone modifications regulate the expression of P450s at a transcriptional level, whereas noncoding RNAs can influence P450 expression at either the transcriptional or post-transcriptional level. Depending on size, a noncoding RNA can be grouped as either small noncoding RNA [ $<200$ nucleotides (nt)], including approximately 22-nt microRNA (miRNA), or long noncoding RNA (lncRNA, >200 nt). Regulation of P450s by miRNAs has been well documented through either direct or indirect interactions between miRNAs and the 3 '-untranslated regions of the $P 450$ mRNAs (Tsuchiya

ABBREVIATIONS: AhR, aryl hydrocarbon receptor; CAR, constitutive androstane receptor; DMEM, Dulbecco's modified Eagle's medium; FBS, fetal bovine serum; GAPDH, glyceraldehyde 3-phosphate dehydrogenase; HNF1 $\alpha$, hepatocyte nuclear factor 1 alpha; HNF1 $\alpha$-AS1, hepatocyte nuclear factor 1 alpha antisense 1; HNF4 $\alpha$, hepatocyte nuclear factor 4 alpha; HNF4 $\alpha$-AS1, hepatocyte nuclear factor 4 alpha antisense 1; IncRNA, long noncoding RNA; miRNA, microRNA; P450s, cytochrome P450s; PXR, pregnane X receptor; qPCR, quantitative polymerase chain reaction; siRNA, small interfering RNA. 
et al., 2006; Pan et al., 2009) or their regulatory nuclear receptor mRNAs (Yu et al., 2016); however, the regulation of $\mathrm{P} 450$ expression by lncRNAs is still being investigated.

LncRNAs can act as either activators or repressors in the regulation of gene expression by directly binding to transcriptional factors or recruiting chromatin-remodeling complexes. In some cases, lncRNAs recruit histone modification enzymes such as WD repeat domain 5/myeloid-lymphoid leukemia protein complexes to promoter regions and activate the transcription of target genes by driving histone $\mathrm{H} 3$ lysine 4 trimethylation (Wang et al., 2011). In other situations, lncRNAs inactivate the transcription of target genes by recruiting polycomb repressive complex-2 and increasing histone H3 lysine 27 trimethylation in promoter regions (Kaneko et al., 2014). Moreover, lncRNAs can also affect the post-transcriptional and translational regulation of target genes by influencing the splicing process of mRNA or binding to translation factors and ribosomes (Ma et al., 2013).

Expression of P450s can also be regulated by lncRNAs. Recently, we reported that the lncRNAs hepatocyte nuclear factor 1 alpha antisense 1 (HNF $1 \alpha$-AS1) and $\mathrm{HNF} 4 \alpha$-AS1, together with nuclear receptors, constitute a regulatory network to control the basal and drug-induced expression of P450s in HepaRG cells (Chen et al., 2018). In the current study, we provide a systematic analysis to determine the role of $\mathrm{HNF} 1 \alpha$ AS1 as well as its neighbor HNF1 $\alpha$ in the regulation of $\mathrm{P} 450$ expression in human liver samples and hepatocarcinoma Huh7 cells. We found that HNF1 $\alpha$-AS1 under the control of HNF $1 \alpha$ is involved in the regulation of basal and drug-induced expression of numerous P450s as well as the transcriptional regulator pregnane $\mathrm{X}$ receptor (PXR), constitutive androstane receptor (CAR), and aryl hydrocarbon receptor (AhR).

\section{Materials and Methods}

Chemicals and Reagents. Dulbecco's modified Eagle's medium (DMEM) and fetal bovine serum (FBS) were purchased from Corning Inc. (Armonk, NY). Opti-MEM was purchased from Thermo Fisher Scientific (51985034; Carlsbad, CA). TriPure isolation reagent was purchased from Roche (Basel, Switzerland). Penicillin and streptomycin mixture, dimethyl sulfoxide (DMSO), and other chemical reagents were provided by Solarbio Science \& Technology Co. (Beijing, China). Primers, SYBR Select Master Mix, small interfering RNA (siRNAs) for HNF1 $\alpha$ (A01003), siRNAs for HNF1 $\alpha$-AS1 (HSS178564), and control siRNAs (A06001) were provided by Thermo Fisher Scientific. Polyvinylidene fluoride (PVDF) membranes were purchased from EMD Millipore (Billerica, MA). HNF1 $\alpha$ expression plasmid was purchased from Genecopoeia (Guangzhou, Guangdong, China), HNF1 $\alpha$-AS1 plasmid was provided by GeneChem Co., Ltd. (Shanghai, China). HNF1 $\alpha$ primary antibody (ab174653; Abcam, Cambridge, UK), glyceraldehyde 3-phosphate dehydrogenase (GAPDH) primary antibody (60004-1-Ig; Proteintech, Wuhan, China), and secondary antibodies (SA00001-1, SA00001-2; Proteintech) were used in Western blot analysis.

Human Liver Tissues. The uses of the liver tissues were approved by the Medical Ethical Committee of First Affiliated Hospital of Zhengzhou University and written consent was obtained from the participating patients. A total of 43 human liver tissues were collected and prepared as described in our previous studies (He et al., 2016; Nie et al., 2017). Information about the 43 liver samples used in this study is provided in Supplemental Tables 3 and 4, including age, sex, race, and pathologic condition.

Cell Culture and Transfection. Human hepatoma cell line Huh7 is a commercially available cell line frequently used as an in vitro system for the of study gene regulation. Huh7 cells were provided by the Type Culture Collection of the Chinese Academy of Sciences (cat. no.
TcHu182; Shanghai, China) and cultured in DMEM supplemented with $10 \%$ FBS and $1 \%$ penicillin and streptomycin mixture. For gene silencing or overexpression experiments, Huh7 cells were transiently transfected with specific siRNAs or expression plasmids using Lipofectamine RNAiMAX Transfection Reagent according to the manufacturer's instructions (Thermo Fisher Scientific). Briefly, Huh7 cells were allowed to grow for up to 24 hour on six-well plates and reached $80 \%-90 \%$ confluence prior to transfection. Then, 40 pmol of siRNAs targeting HNF $1 \alpha$, HNF $1 \alpha$-AS1, or control siRNAs were mixed with RNAiMAX reagent in minimum essential medium and added into the culture medium. In overexpression studies, $2.5 \mu \mathrm{g}$ of plasmids were used for each well. At 24 hours after transfection, the culture medium was replaced with DMEM supplemented with $2 \%$ FBS and incubated for another 24 hours. For drug induction studies, transfected cells were incubated with rifampicin $(10 \mu \mathrm{M})$ or DMSO $(0.1 \%, \mathrm{v} / \mathrm{v})$ for 24 hours before harvested.

RNA Isolation and Real-Time Quantitative Polymerase Chain Reaction. Total RNA from liver tissues or cultured cells was isolated using the TriPure isolation reagent according to the manufacturer's instruction (Basel, Switzerland). The quality and concentrations of RNAs were analyzed by a Nanodrop 2000c Spectrophotometer (Thermo Fisher Scientific). For mRNA expression analysis, total RNAs were reversely transcribed using a PrimeScript RT reagent kit and quantitative polymerase chain reaction (qPCR) reactions were performed by a SYBR method as previously described (Nie et al., 2017). Primers are shown in Supplemental Table S1.

LncRNA Microarray Analysis. Total RNAs from the selected liver tissues were isolated using TRIzol reagent (10296028; Thermo Fisher Scientific) and the expression profiles of lncRNAs were determined by lncRNA microarray chips $(4 \times 180 \mathrm{~K}$; Agilent Technologies, Santa Clara, CA). Data were extracted with Feature Extraction software 10.7 (Agilent Technologies) and raw data were normalized using the Quantile algorithm, GeneSpring Software 11.0 (Agilent Technologies). LncRNA microarray and data analysis were performed by Shanghai Biotechnology Corporation (Shanghai, China).

Western Blot Analysis. Total proteins of the liver tissues or treated cells were prepared using a RIPA buffer $(150 \mathrm{mM} \mathrm{NaCl}, 1 \%$ NP-40, 0.5\% sodium deoxycholate, $0.1 \%$ SDS, and 50 mM Tris, $\mathrm{pH} 8.0$ ), and protein concentrations were determined using a previously described method (Nie et al., 2017; Yan et al., 2017). Protein samples were separated by $12 \%$ SDS-polyacrylamide gel electrophoresis and transferred to PVDF membranes. After being blocked for 2 hours in 5\% nonfat milk, membranes were incubated with primary antibodies for HNF $1 \alpha$ or GAPDH overnight at $4^{\circ} \mathrm{C}$. Primary antibodies were diluted as follows: anti-HNF $1 \alpha(1: 1000$; rabbit polyclonal) and anti-GAPDH (1:10000; mouse monoclonal). The membranes were then incubated in horseradish peroxidase-labeled secondary antibodies in blocking buffer for 2 hours and visualized with an enhanced chemiluminescence method. GAPDH protein was used as a loading control.

Statistical Analysis. All in vitro experiments with Huh7 cells described here were performed as three independent experiments. Data are shown as the means \pm S.D. Statistical significances between groups were analyzed by two-tailed unpaired Student's $t$ test using SPSS version 17.0 (IBM Corp., Armonk, NY). Pearson's correlation analysis was performed to assess the correlations of gene expression between $\mathrm{HNF} 1 \alpha$-AS1 and P450s as well as nuclear receptors in the 43 liver tissue samples using Prism 6 from GraphPad (La Jolla, CA).

\section{Results}

LncRNA Expression Profiles in Liver Tissues. The expression levels of mRNA and protein of CYP3A4 in liver tissues were measured by qPCR and Western blot. Two groups were set according to the expression levels of CYP3A4: Group A contained three samples with a high level of CYP3A4 expression for both mRNA and protein and group B contained three samples with a low level of CYP3A4 (Fig. 1, A and B). 
A

CYP3A4 mRNA

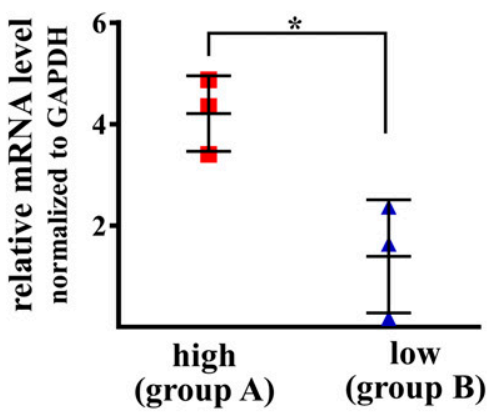

B

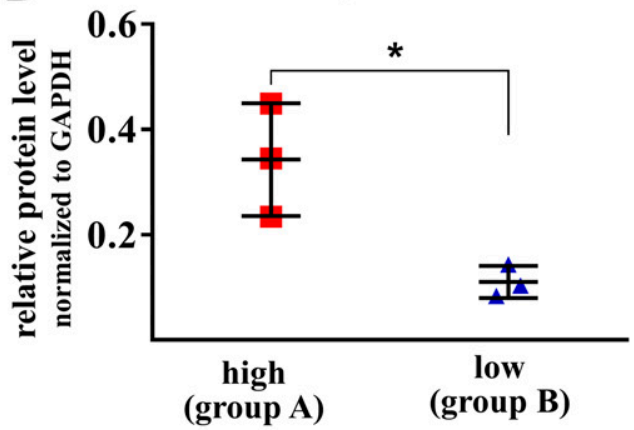

C

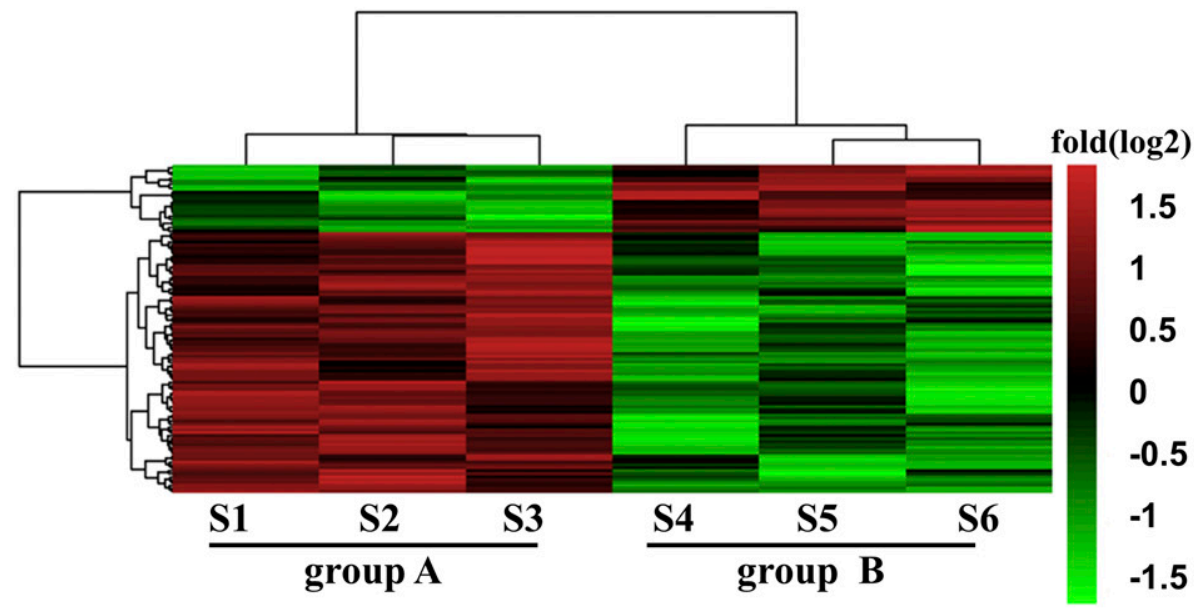

Fig. 1. LncRNA expression profiles in liver tissues. (A) The mRNA levels of CYP3A4 in six liver tissues subjected to lncRNA microarray. (B) The protein levels of CYP3A4 in six liver tissues subjected to lncRNA microarray. Data are shown as the mean \pm S.D. ${ }^{*} P<0.05$, two-tailed unpaired Student's $t$ test. (C) Heat map of the expression profiles of lncRNAs in six liver tissues with fold changes in $\log _{2}$ scale. Colors represent the higher (red) or lower (green) expression of lncRNAs. (D) The top 10 upregulated lncRNAs in group $\mathrm{A}$, which contained three samples with high levels of CYP3A4.

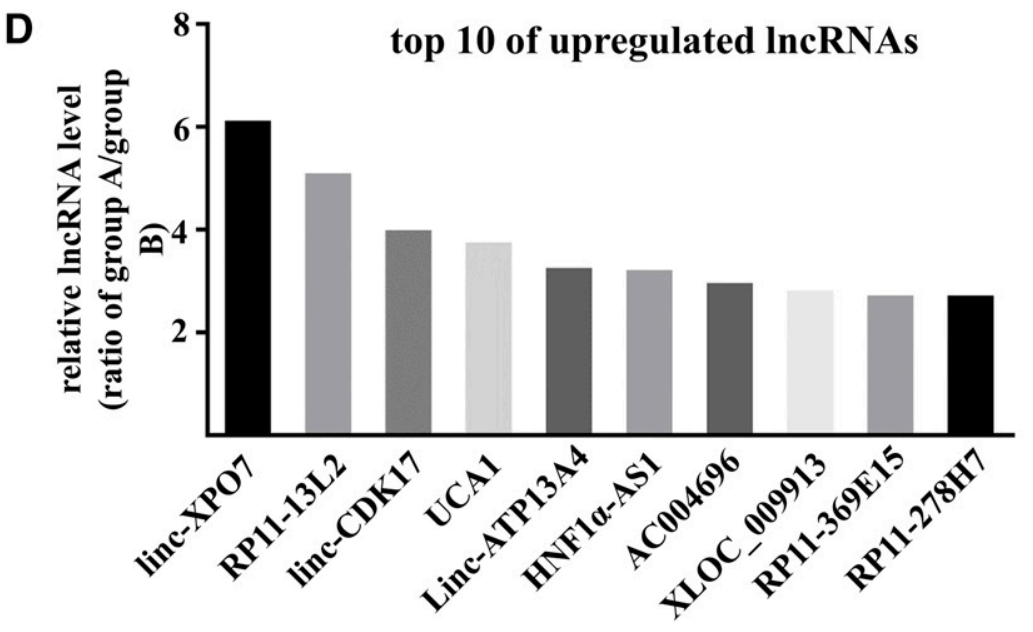

The differences in mean mRNA and protein between groups A and B were 3.0- and 3.1-fold, respectively. Expression profiles were then analyzed in each group using a microarray assay specific for lncRNAs. A total of 112 lncRNA transcripts were identified as differently expressed between the two groups (fold difference $>2.0, P<0.05$, Fig. 1C). Among these, 89 lncRNA transcripts were higher in group $A$ than in group $B$, whereas 23 transcripts were lower. Among the top 10 increased lncRNAs in group A, lncRNA HNF $1 \alpha$-AS1 was ranked at sixth with a 3.3 -fold difference (Fig. 1D).

Evolutionary Conservation of HNF1 $\alpha$ and HNF1 $\alpha$-AS1 DNA Sequences. The $H N F 1 \alpha-A S 1$ gene is located at chromosome 12 between 120,941,728 and 120,980,771 in the annotated
Human GRCh38/hg38 Genome and has a genomic sequence of $39.04 \mathrm{~kb}$ spanning two exons and 1 intron on the antisense strand (Fig. 2A). In the 3 '-direction, the next gene encodes HNF1A at chromosome 12 between 120,978,543 and 121,002,512 in the Human GRCh38/hg38 Genome and has a genomic sequence of $23.97 \mathrm{~kb}$ spanning 10 exons and 9 introns on the sense strand. The genomic locus of $H N F 1 A$ and $H N F 1 \alpha-A S 1$ genes forms a typical pair of sense coding genes and neighbor antisense noncoding gene. Analysis of the conservation levels of the DNA sequences of HNF $1 \alpha$ and HNF $1 \alpha$-AS 1 was performed using HomoloGene from NCBI (www.ncbi.nlm.nih.gov/ homologene/459), UCSC genomic browser (www.genome. ucsc.edu), and NONCODE (www.noncode.org). The results 
A

Human

Chromosome 12

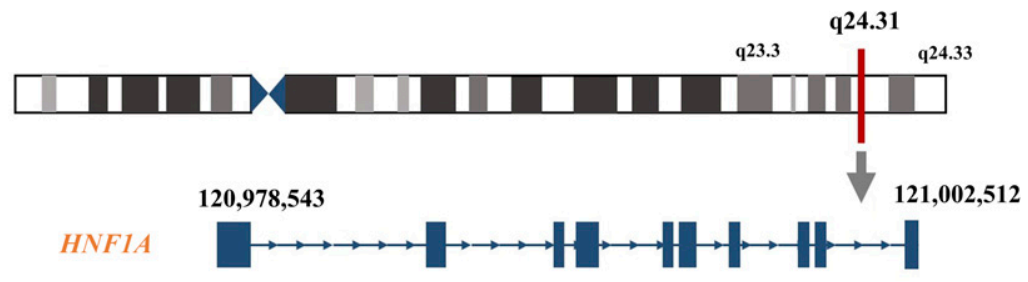

$120,980,771$

$120,941,728$

B

Conservation of $\mathrm{HNF1A}$

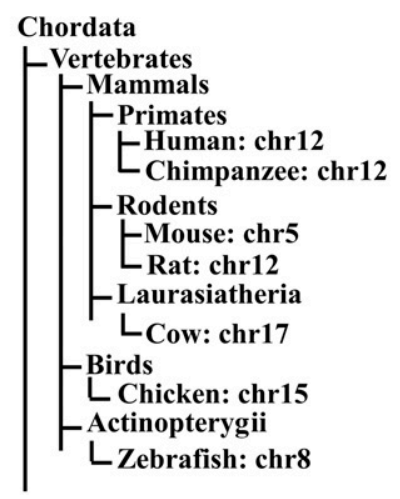

\section{C}

\section{Conservation of $H N F 1 \alpha-A S 1$}

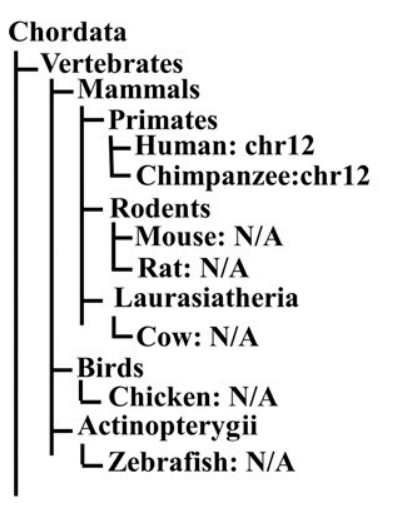

Fig. 2. DNA sequence conservation of $\mathrm{HNF} 1 \alpha$ and $\mathrm{HNF} 1 \alpha-\mathrm{AS} 1$ across various species. (A) Genomic location of the HNF1A and $H N F 1 \alpha-A S 1$ genes in the Human GRCh38/h38 Genome. (B and C) Conservation levels (\% identity) of the entire gene sequences of $H N F 1 A$ (B) and $H N F 1 \alpha-A S 1$ (C) among species in comparison with human. The sequences are derived from the NCBI and NONCODE databases. NA, not available. indicated that the human DNA sequences of HNF1 $\alpha$ are highly conserved with those of other mammals (approximately 90\%) and birds (approximately 75\%) as well as fish (zebrafish, approximately 60\%) (Fig. 2, B and C), indicating its probable importance in physiologic processes across the species. However, the human HNF1 $\alpha$-AS1 sequence showed a much lower level of conservation, having been conserved only within mammals $(>60 \%)$ and showing no conservation in birds and fish (Fig. 2, B and C).

Tissue-Specific Expression Patterns of $H N F 1 A$ and HNF1 $\alpha$-AS1 RNAs. The protein encoded by the HNF1A gene is a well-studied transcription factor controlling the expression of numerous liver-specific genes. A specific tissue distribution pattern of HNF1A mRNA was retrieved from the RNA-Seq Expression Data GTEx in 53 tissues from 570 donors (GTEx Consortium, 2013), which showed relatively high expression levels in the stomach, liver, pancreas, small intestine, colon, and kidney, the major organs in the gastrointestinal tract (Supplemental Fig. S1A). A very similar tissue distribution pattern in the gastrointestinal tract organs was also found for HNF1 $\alpha$-AS1 (Supplemental Fig. S1B), indicating that $\mathrm{HNF} 1 \alpha$-AS 1 is expressed in the same organs as $\mathrm{HNF} 1 \alpha$. These results suggested that $\mathrm{HNF} 1 \alpha$ may control general physiologic processes for gastrointestinal functions, whereas $\mathrm{HNF} 1 \alpha$-AS1 is possibly involved in physiologic processes for gastrointestinal functions in a more species-specific manner in mammals. These results further supported the value of examining the roles of $\mathrm{HNF} 1 \alpha$ and $\mathrm{HNF} 1 \alpha$-AS1 in the regulation of drug-metabolizing P450 enzymes.

Correlations between HNF1 $\alpha$-AS1 and P450s as well as Transcriptional Regulators in Liver Tissues. To further study the relationships between $\mathrm{HNF} 1 \alpha-\mathrm{AS} 1$ and
$\mathrm{P} 450$ s as well as transcriptional regulators in human liver, the RNA levels of HNF1 $\alpha$-AS1, HNF1 $\alpha$, P450s (CYP1A2, 2B6, 2C8, 2C9, 2C19, 2D6, 2E1, and 3A4), and transcriptional regulators (PXR, CAR, and $\mathrm{AhR}$ ) were measured in 43 liver tissues using qPCR, and the correlations between them were analyzed using Pearson's correlation coefficient (Fig. 3; Supplemental Fig. S2; Supplemental Table S2). The results indicated that the RNA levels of the target genes presented considerable individual differences among the 43 samples (Supplemental Fig. S2) and the correlations between different mRNAs were varied (Supplemental Table S2). Specifically, the expression of $H N F 1 \alpha-A S 1$ RNA showed a statistically significant correlation with the expression of $H N F 1 A$ mRNA (Fig. 3A, $r=0.447, P=0.002$ ) and major P450s examined, including CYP2C8 (Fig. 3B, $r=0.498, P=0.0007$ ), $2 \mathrm{C} 9$ (Fig. $3 \mathrm{C}, r=0.535, P=0.0002$ ), $2 \mathrm{C} 19$ (Fig. $3 \mathrm{D}, r=0.360, P=$ 0.018 ), $2 \mathrm{D} 6$ (Fig. $3 \mathrm{E}, r=0.538, P=0.0002$ ), $2 \mathrm{E} 1$ (Fig. $3 \mathrm{~F}, r=$ $0.391, P=0.009$ ), and 3A4 (Fig. 3G, $r=0.503, P=0.0006$ ) as well as PXR (Fig. 3H, $r=0.602, P<0.0001$ ) and CAR (Fig. 3I, $r=0.676, P<0.0001)$.

HNF1 $\alpha$ Regulates the Expression of HNF1 $\alpha$-AS1, P450s, and Nuclear Receptors in Huh7 Cells. To uncover the impact of $\mathrm{HNF} 1 \alpha$ on the transcriptional expression of $\mathrm{HNF} 1 \alpha-\mathrm{AS} 1$, $\mathrm{P} 450 \mathrm{~s}$, as well as transcriptional regulators, silencing and overexpression of HNF $1 \alpha$ were performed in Huh7 cells. A decrease in HNF $1 \alpha$ mRNA and protein was confirmed after siRNA knockdown of HNF1 $\alpha$ (Fig. 4 , A and B). A decrease in HNF1 $\alpha$-AS1 (10\% of the control) was also observed after knocking down the expression of $\mathrm{HNF} 1 \alpha$ (Fig. 4A). In addition, the mRNA levels of CYP2B6, 2C8, 2C9, 2D6, 2E1, and 3A4, as well as CAR and PXR, were also decreased in the HNF1 $\alpha$ knockdown cells, whereas the expression of CYP1A2 and AhR was increased 


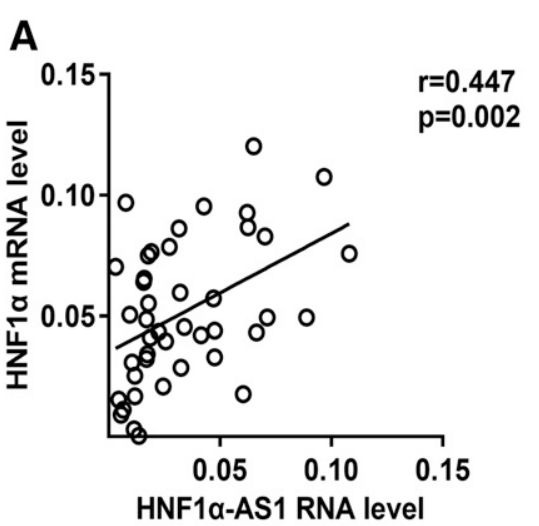

D
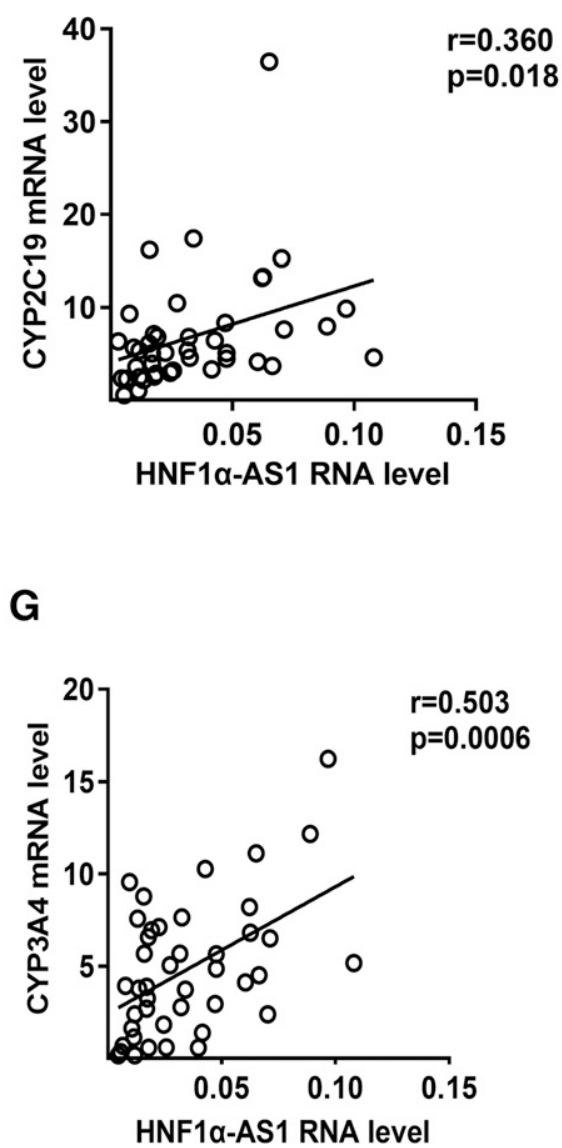

B

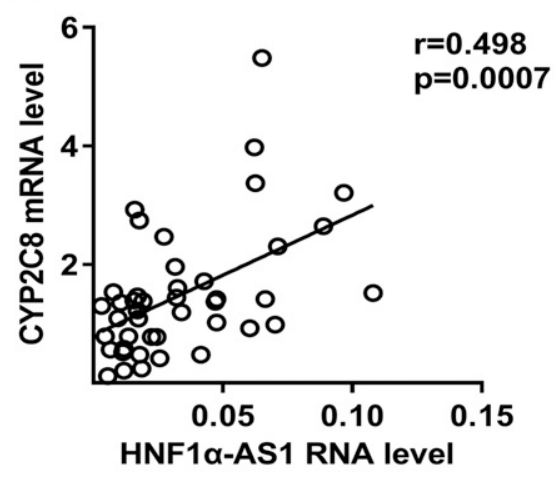

E

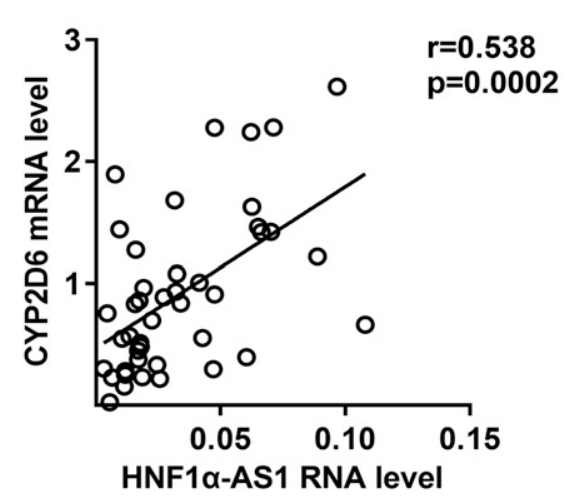

H

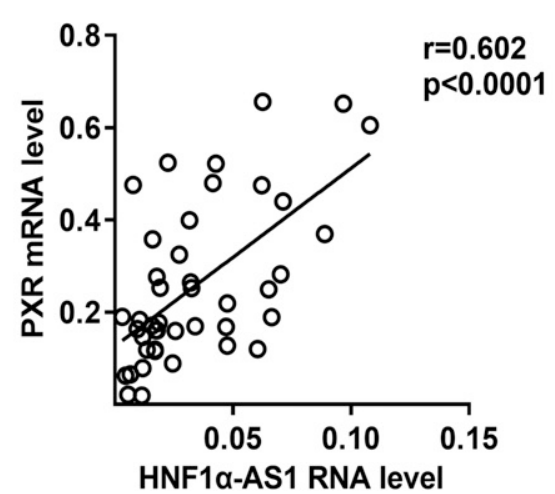

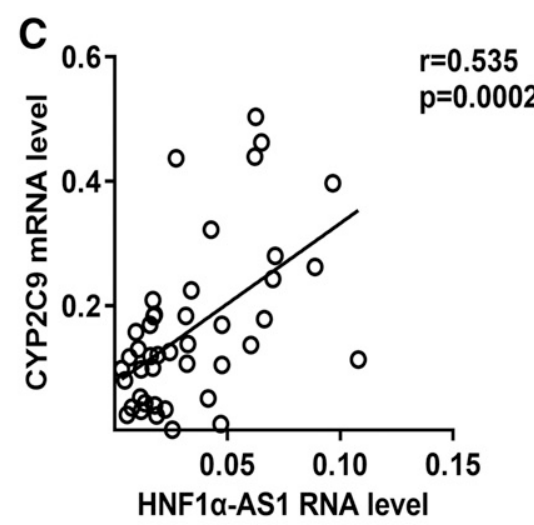

F

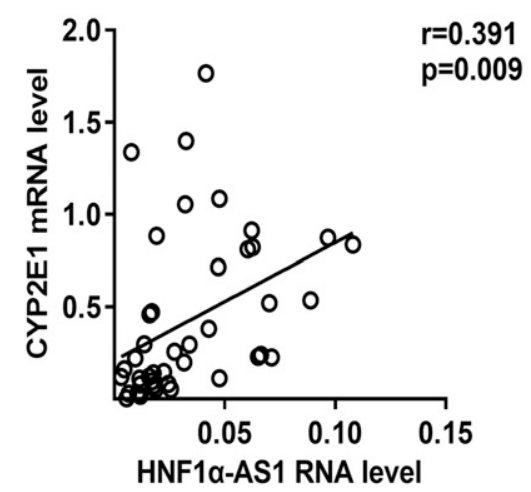

I

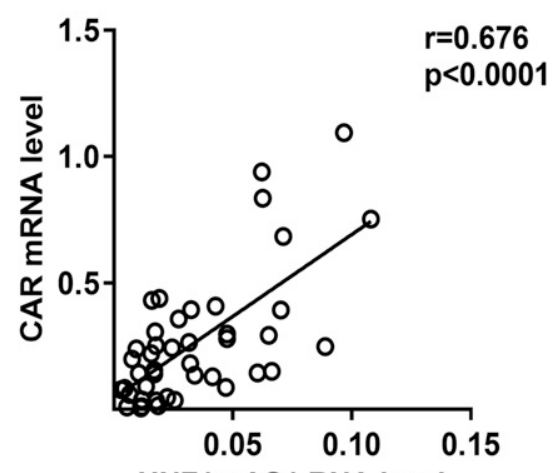

HNF1a-AS1 RNA level

Fig. 3. Correlations of the RNA level of HNF1 $\alpha$-AS1 with that of HNF1 $\alpha$ (A), CYP2C8 (B), 2C9 (C), 2C19 (D), 2D6 (E), 2E1 (F), 3A4 (G), PXR (H), and CAR (I) in 43 human liver tissue samples. Pearson's correlation coefficients $(r)$ were calculated by two-tailed Pearson's correlation analysis.

(Fig. 4, C and D). Moreover, knockdown of the expression of HNF1 $\alpha$ also reduced the induction fold of CYP2B6, 2D6, 2E1, and $3 \mathrm{~A} 4$ by rifampicin but increased the induction of CYP1A2 (Fig. 4E).

Overexpression of HNF $1 \alpha$ mRNA and protein levels was confirmed by transfection of an expression plasmid containing the HNF1A gene (Fig. 5A). An increase in HNF1 $\alpha$-AS1 (Fig. 5B), as well as CYP2B6, 2C9, 2D6, and 3A4 (Fig. 5D), was found in the cells with overexpression of HNF1 $\alpha$ in comparison with the control plasmid, whereas a decrease in CYP1A2 and $A H R$ mRNA expression was observed (Fig. 5, C and D). The induction of CYP2B 6 and 2D6 by rifampicin was also increased by HNF1 $\alpha$ overexpression (Fig. 5E). These findings suggested that the alterations of HNF $1 \alpha$ expression resulted in changes of basal and rifampicin-induced expression of major P450s via changes of HNF1 $\alpha$-AS1 and the transcriptional regulators PXR, CAR, and AhR.

HNF1 $\alpha$-AS1 Regulates the Expression of P450s and PXR, but Not HNF1 $\alpha$, CAR, and AhR. To explore the role of $\mathrm{HNF} 1 \alpha-\mathrm{AS} 1$ in the regulation of $\mathrm{P} 450$ s and transcriptional 
A
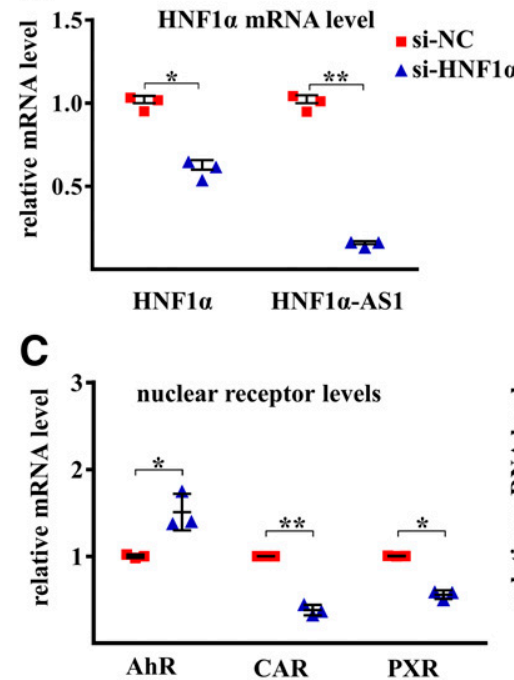

$\mathbf{E}$

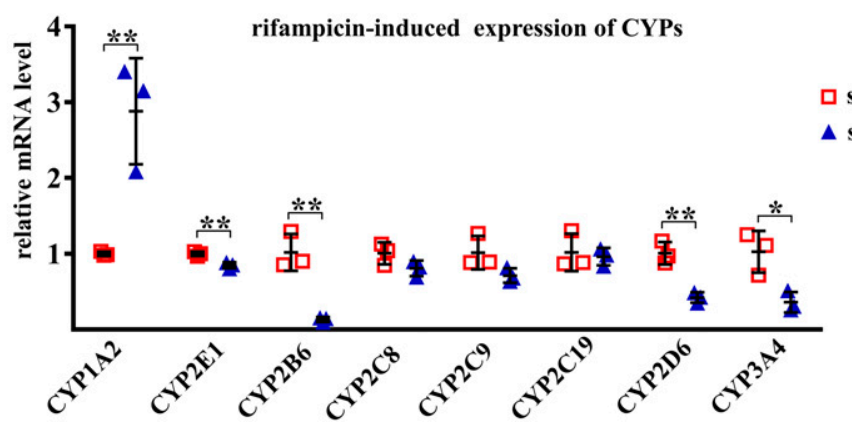

B

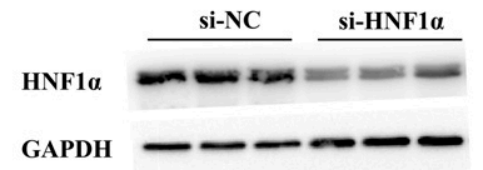

D

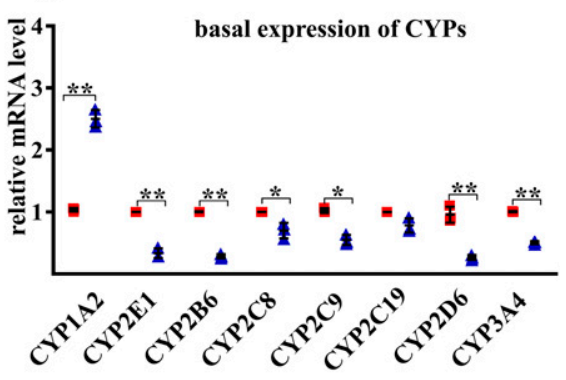

Fig. 4. Effects of HNF $1 \alpha$ knockdown on the mRNA expression of the studied genes. (A) mRNA expression of HNF $1 \alpha$ and RNA level of HNF1 $\alpha$-AS1 in siRNA negative control (si-NC) and siRNA HNF $1 \alpha($ si-HNF1 $\alpha)$ transfected Huh7 cells. (B) Protein level of HNF1 $\alpha$ in control si-NC- and si-HNF1 $\alpha$ transfected Huh7 cells. (C) Impact of HNF $1 \alpha$ knockdown on the expression of $A H R, C A R$, and PXR mRNAs. (D) Impact of HNF $1 \alpha$ knockdown on the basal expression of $P 450$ mRNAs. (E) Impact of HNF $1 \alpha$ knockdown on the rifampicin-induced expression of P450 mRNAs. Data points from three independent experiments are shown as dots along with the mean \pm S.D., $* P<0.05$; $* * P<0.01$ in comparison of si-HNF1 $\alpha$ with the si-NC group by two-tailed unpaired Student's $t$ test. regulators, RNA interference and overexpression were performed in Huh7 cells by using transient transfection of siRNAs or expression plasmids of $\mathrm{HNF} 1 \alpha-\mathrm{AS} 1$. SiRNA treatment showed the knockdown of $\mathrm{HNF} 1 \alpha$-AS1 to approximately $50 \%$ of siRNA control (Fig. 6A). After knockdown of HNF1 $\alpha$-AS1 expression, no alteration was observed for the mRNA levels of HNF1 $\alpha$, AhR, or CAR (Fig. 6, A and B), whereas the expression of PXR mRNA as well as the mRNAs of CYP2B6, 2C8, 2C9, 2D6, 2E1, and 3A4 was reduced, whereas that of CYP1A2 was increased (Fig. 6, B and C). The induction of most CYPs by rifampicin was also decreased after knockdown of HNF1 $\alpha$-AS1, including CYP1A2, 2C8, 2C19, 2D6, 2E1, and 3A4 (Fig. 6D).

Overexpression of HNF1 $\alpha$-AS1 by transfection with an HNF1 $\alpha$-AS1 plasmid in Huh7 cells showed a 30-fold increase in $\mathrm{HNF} 1 \alpha$-AS1 in comparison with that from a control plasmid (Fig. 7A). An increase in PXR mRNA without an effect on the expression of $A H R$ and $C A R$ mRNA was observed (Fig. 7B). However, the basal expression levels of most P450 mRNAs remained unchanged except for CYP1A2 and 2E1 (Fig. 7C). Furthermore, no effect of HNF1 $\alpha$-AS1 overexpression was observed on rifampicin-induced expression of P450s except for an increase in CYP1A2 induction (Fig. 7D). These results suggested that endogenous expression of HNF1 $\alpha$-AS1 is needed in the regulation of PXR as well as most P450s, and the regulation of the transcription of $\mathrm{P} 450 \mathrm{~s}$ by $\mathrm{HNF} 1 \alpha$ may be mediated by alteration of both $\mathrm{HNF} 1 \alpha-\mathrm{AS} 1$ and transcriptional regulators.

\section{Discussion}

Expression of $\mathrm{P} 450 \mathrm{~s}$ in liver cells is largely regulated at transcriptional levels by nuclear receptors. HNF $1 \alpha$ and $\mathrm{HNF} 4 \alpha$ are two key transcription factors in the regulation of basal expression of P450s (Liu and Gonzalez, 1995; Jover et al., 2001; Cheung et al., 2003; Kamiyama et al., 2007), whereas PXR and CAR are two key transcription factors in the control of drug-induced expression of P450s (Goodwin et al., 1999; Waxman, 1999; Tompkins and Wallace, 2007). PXR and CAR often require crosstalk with $\mathrm{HNF} 1 \alpha$ and $\mathrm{HNF} 4 \alpha$ as coactivators (Tirona et al., 2003; Li and Chiang, 2006). HNF1 $\alpha$ is a liver-enriched transcription factor, the overexpression of which in HepG2 cells enhances the expression of CYP3A4, 1A1, and 2C9 (Chiang et al., 2014). In the current study, strong correlations between the mRNA level of HNF $1 \alpha$ and transcriptional regulators PXR, CAR, and AhR, as well as several P450s in human liver tissues, were observed (Supplemental Table S2). Loss- and gain-of-function studies showed that alteration of the HNF $1 \alpha$ expression directly resulted in changes to the mRNA levels of PXR, CAR, and AhR (Fig. 4C; Fig. 5C). The regulatory mechanisms may be associated with direct binding of HNF1 $\alpha$ on the target promoters, as it has been reported that an $\mathrm{HNF} 1 \alpha$-binding site is located in the PXR promoter (Uno et al., 2003; Aouabdi et al., 2006). More importantly, the expression of HNF $1 \alpha$ also showed obvious impact on the basal and rifampicin-induced expression of 
A HNF1 a mRNA level
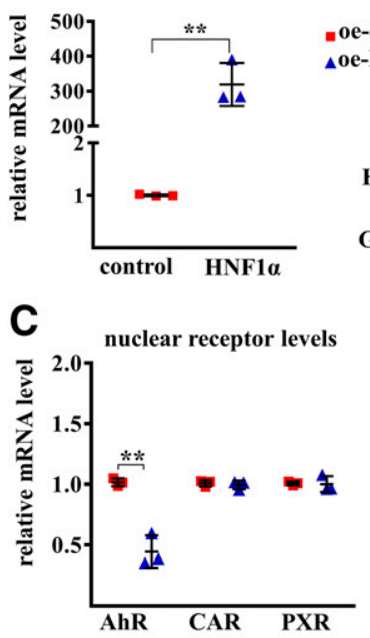

E

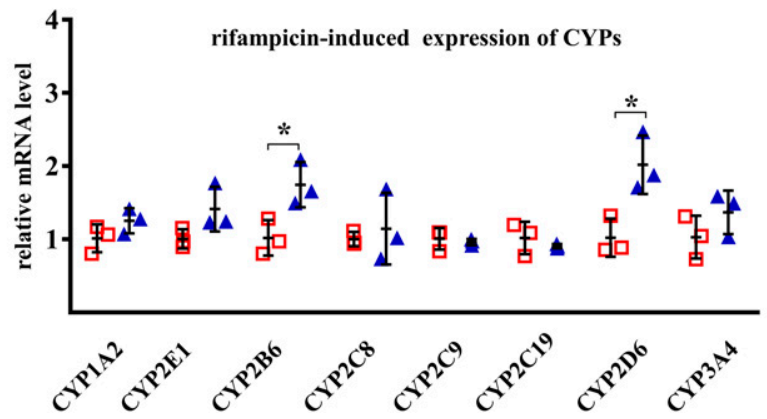

B HNF1a-AS1 level
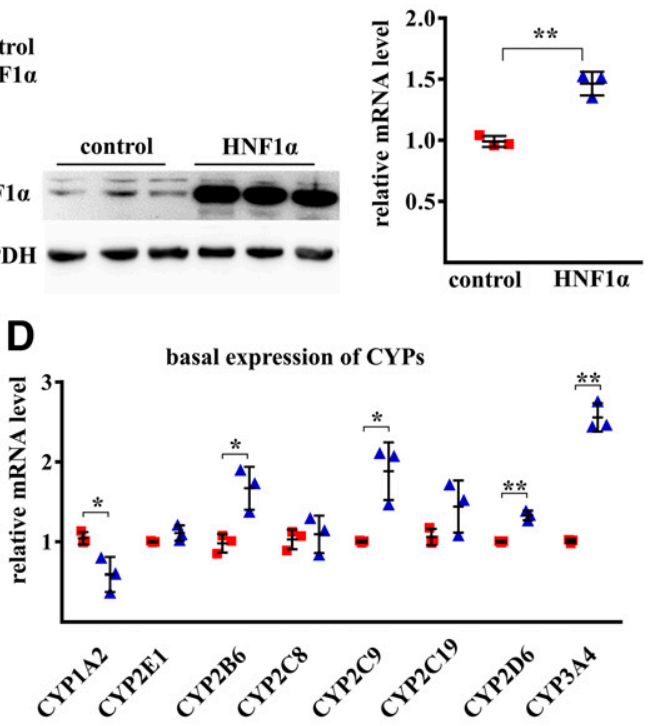

oe-control+RIF

$\triangle$ oe-HNF1a+RIF
Fig. 5. Effects of HNF $1 \alpha$ overexpression on the mRNA levels of the studied genes. (A) mRNA and protein levels of HNF $1 \alpha$ in control and HNF $1 \alpha$-overexpressing (oe) Huh7 cells. (B) Impact of HNF1 $\alpha$ overexpression on the expression of $H N F 1 \alpha-A S 1$ RNA in control and HNF $1 \alpha-$ overexpressing Huh7 cells. (C) Impact of HNF1 $\alpha$ overexpression on the expression of $A H R, C A R$, and PXR mRNAs. (D) Impact of HNF1 $\alpha$ overexpression on the basal expression of P450 mRNAs. (E) Impact of HNF1 $\alpha$ overexpression on the rifampicin-induced expression of $P 450$ mRNAs. Data points from three independent experiments are shown as dots along with the mean \pm S.D., $* P<0.05$ $* * P<0.01$ in comparison of overexpressing HNF $1 \alpha$ with the control group by two-tailed unpaired Student's $t$ test. several P450s (Fig. 4, D and E; Fig. 5, D and E). These results were in accordance with our recently published study in HepaRG cells (Chen et al., 2018).Together with previous studies, the current findings support $\mathrm{HNF} 1 \alpha$ as a key regulator of both the transcriptional regulators and $\mathrm{P} 450 \mathrm{~s}$.

However, the regulatory mechanisms behind the impact of HNF $1 \alpha$ on the expression of transcriptional regulators and $\mathrm{P} 450$ s are far from being well understood. In this study, the role of lncRNA HNF1 $\alpha$-AS1 in the $\mathrm{HNF} 1 \alpha$-mediated regulation of P450 expression in liver cells was determined. LncRNAs have attracted much more attentions owing to their irreplaceable functions in the regulation of many physiologic processes (Khorkova et al., 2015). LncRNAs can interact with a wide range of biologic molecules to regulate gene expression, such as proteins, DNAs, and RNAs (Villegas and Zaphiropoulos, 2015). In particular, a large group of proteins that interact with lncRNAs are transcriptional factors. For example, the lncRNA long-intergenic noncoding Linc-YY1, derived from the promoter of transcriptional factor YY1, interacts with YY1 to remove the YY1/polycomb repressive complex from target promoters, which leads to activation of downstream genes and promotes muscle regeneration (Zhou et al., 2015). Interactions of transcription factors with their genomic neighboring lncRNAs, particularly for sense-antisense pairs, have been considered as a general biologic phenomenon (Kung et al., 2013; Herriges et al., 2014). Transcriptional factor-derived lncRNAs often participate in the regulatory activities of their paired transcriptional factors (Zhou et al., 2015). Therefore, it is logical to speculate that the
HNF $1 \alpha$-mediated transcription regulation of $\mathrm{P} 450 \mathrm{~s}$ and transcriptional regulators may require involvement of its neighboring antisense lncRNAs.

The involvement of lncRNA HNF $1 \alpha-\mathrm{AS} 1$ in $\mathrm{HNF} 1 \alpha$ regulatory function was first determined in an initial study wherein we screened differently expressed lncRNAs associated with differential expression of CYP3A4. Differentially expressed lncRNAs determined via microarray analysis identified a set of candidate lncRNAs (Fig. 1C), which included lncRNA HNF $1 \alpha-\mathrm{AS} 1$ in a list of the top associated lncRNAs (Fig. 1D). The $H N F 1 \alpha-A S 1$ gene is located next to the HNF1A gene on the antisense strand in chromosome 12 (Fig. 2A). Compared with the HNF1A DNA sequence, the HNF1 $\alpha$-AS1 sequence is much less frequently conserved outside of mammals (Fig. 2, B and C), implying a certain extent of involvement of $\mathrm{HNF} 1 \alpha$-AS1 in $\mathrm{HNF} 1 \alpha$ regulatory function in the mammalian liver.

The involvement of $\mathrm{HNF} 1 \alpha-\mathrm{AS} 1$ in $\mathrm{HNF} 1 \alpha$ regulatory function was further demonstrated in a correlation study with 43 human liver tissue samples (Fig. 3). Expression of HNF1 $\alpha$ AS1 was found to be statistically significantly correlated with the mRNA expression levels of most selected P450s as well as that of $\mathrm{HNF} 1 \alpha, \mathrm{CAR}$, and PXR in the human liver tissues (Fig. 3, $P<0.05,0.01$, or 0.001 in Pearson correlation analysis).

The involvement of $\mathrm{HNF} 1 \alpha-\mathrm{AS} 1$ in $\mathrm{HNF} 1 \alpha$ regulatory function on P450 expression is supported by loss- or gain-of-function studies in human Huh7 cells. Alterations of HNF1 $\alpha$-AS1 expression by either siRNA knockdown or plasmid overexpression 

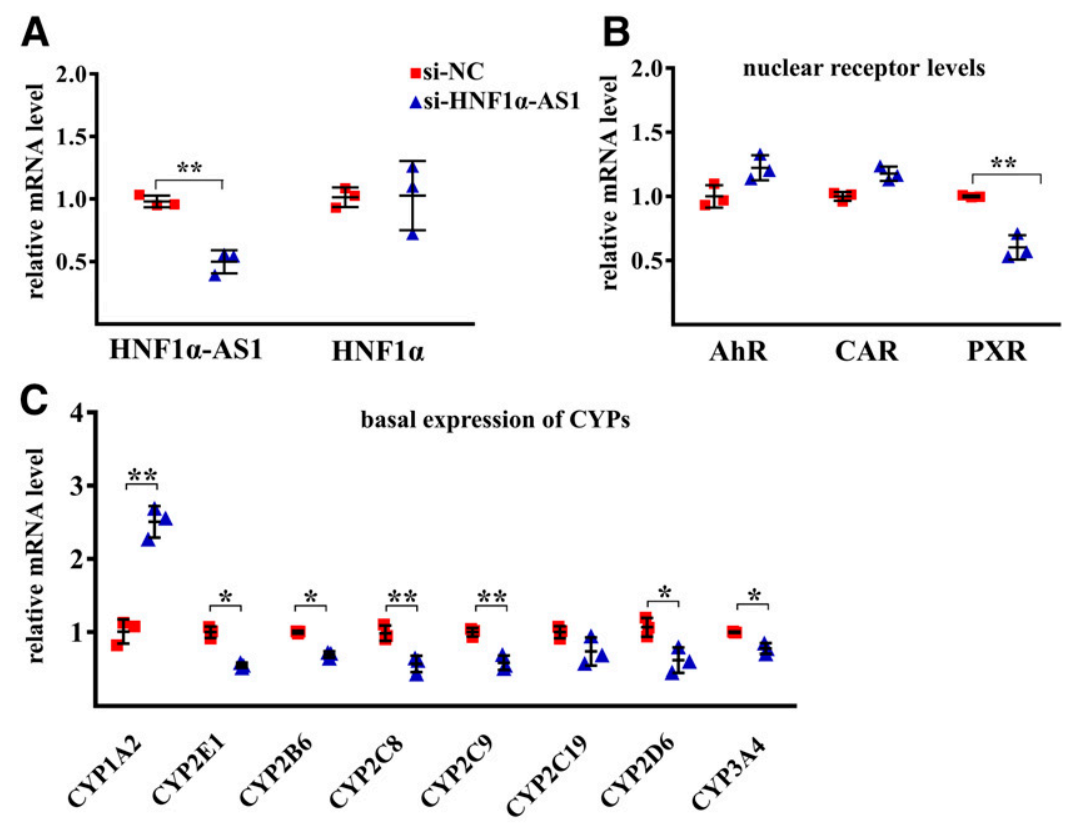

Fig. 6. Effects of HNF1 $\alpha$-AS1 knockdown on the mRNA expression of the studied genes. (A) Expression levels of HNF $1 \alpha$-AS 1 and HNF $1 \alpha$ in siRNA negative control (si-NC) and siRNA HNF1 $\alpha$-AS1(si-HNF1 $\alpha$-AS1)-transfected Huh7 cells. (B) Impact of HNF1 $\alpha$-AS1 knockdown on the expression of $A H R, C A R$, and PXR mRNAs. (C) Impact of HNF1 $\alpha$-AS1 knockdown on the basal expression of P450 mRNAs. (D) Impact of $\mathrm{HNF} 1 \alpha$-AS1 knockdown on the rifampicin-induced expression of P450 mRNAs. Data points from three independent experiments are shown as dots along with the mean \pm S.D., $* P<0.05 ; * * P<0.01$ in comparison of si-HNF $1 \alpha$-AS1 with the control si-NC by two-tailed unpaired Student's $t$ test.

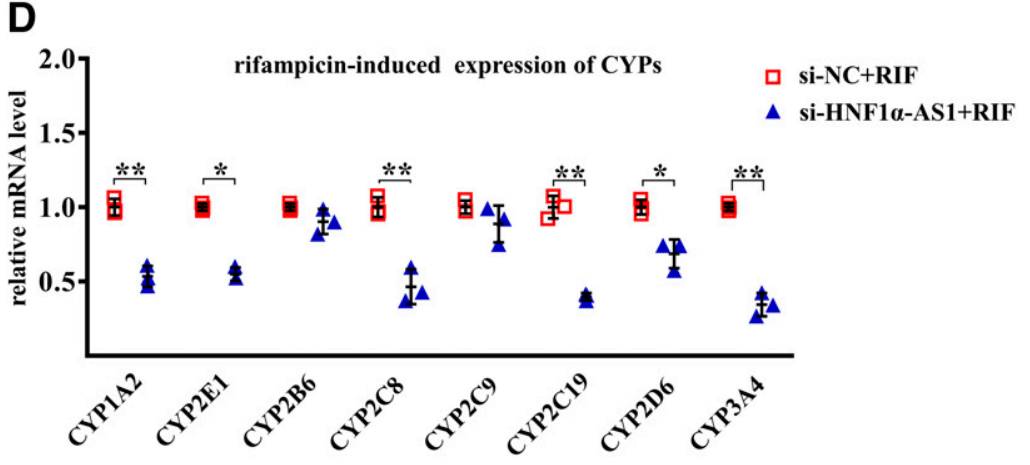

directly resulted in significant changes to the mRNA levels of numerous $\mathrm{P} 450$ s tested as well as transcriptional regulators (Figs. 6 and 7) without a concomitant change of $\mathrm{HNF} 1 \alpha$, suggesting that a network composed of $\mathrm{HNF} 1 \alpha$ and $\mathrm{HNF} 1 \alpha$-AS 1 is the upstream regulator of nuclear receptors, which then further mediate the basal and drug-induced P450 expression. Knockdown of the endogenous expression of HNF1 $\alpha$-AS1 showed similar effects on the basal expression of $\mathrm{P} 450$ s compared with that obtained from silencing the expression of HNF1 $\alpha$ (Fig. 4D; Fig. 6C). However, among the three transcriptional regulators, only PXR mRNA was affected by knockdown of HNF1 $\alpha$-AS1 (Fig. 6B).We found that knockdown of HNF1 $\alpha$-AS1 in Huh7 cells did not affect the $A h R$ mRNA level but significantly increased the CYP1A2 mRNA level, inconsistently with the result in liver tissue in Supplemental Fig. 2. Functional experiments may not be sufficient to detect CAR and AhR effects, because the basal expression level of CAR and AhR is lower in huh7 cells (data not shown). There may be other differences in expression of transcription factors between different cell types. We have previously reported that lncRNA transcription factors and receptors form a complex regulatory network that regulates P450 enzyme expression (Chen et al., 2018). Therefore, we speculate that the regulation of CYP1A2 is a complex process that requires additional in-depth study. In addition, the impact of $\mathrm{HNF} 1 \alpha$-AS 1 knockdown on rifampicininduced expression of P450s was also not identical to that obtained with HNF $1 \alpha$ knockdown. Specifically, the impact on the induction of CYP1A2, 2C8, and $2 \mathrm{C} 19$ by HNF $1 \alpha-\mathrm{AS} 1$ knockdown was different compared with that from knockdown of HNF $1 \alpha$ (Fig. 4E; Fig. 6D). Moreover, exogenous expression of HNF1 $\alpha$-AS1 also showed different effects on the basal and rifampicin-induced expression of $\mathrm{P} 450 \mathrm{~s}$ compared with that consequent to HNF1 $\alpha$ overexpression (Fig. 5, D and E; Fig. 7, $\mathrm{C}$ and $\mathrm{D})$, although the same effect on the transcription of PXR was observed (Fig. 7B). We have not yet found a reasonable explanation for these data and will continue to determine the underlying mechanisms for the induction of CYP1A2 in the HNF1 $\alpha$-AS1 overexpression experiment. However, it could be concluded that the HNF $1 \alpha$ and HNF $1 \alpha-\mathrm{AS} 1$ pair is involved in PXR-mediated basal expression of $\mathrm{P} 450$ genes but may function in different ways with regard to their induced expression.

A detailed determination of the mechanisms by which HNF $1 \alpha$-AS 1 is involved in the HNF $1 \alpha$-mediated regulatory function in liver cells will require further analyses. The physiologic functions of HNF $1 \alpha$-AS 1 were first identified in the regulation of cell proliferation and migration in esophageal adenocarcinoma cells (Yang et al., 2014). The role of $\mathrm{HNF} 1 \alpha$-AS1 in the promotion of cancer progression and metastasis in gastrointestinal tract organs has been reported, including in pancreatic cancer (Muller et al., 2015), gastric cancer (Dang et al., 2015), and hepatocellular carcinoma (Liu et al., 2016). HNF1 $\alpha$-AS1 has been considered an oncogene 
A

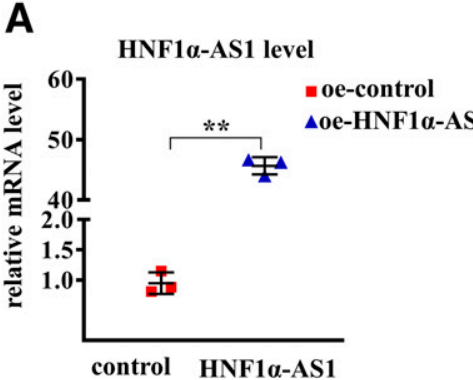

\section{B}

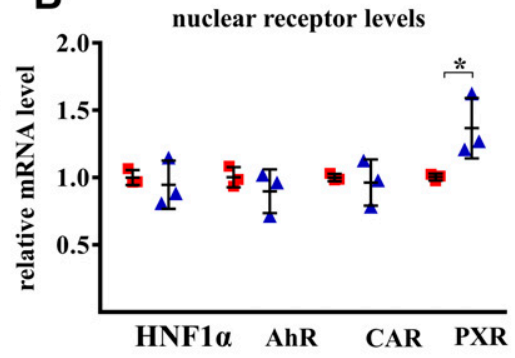

C
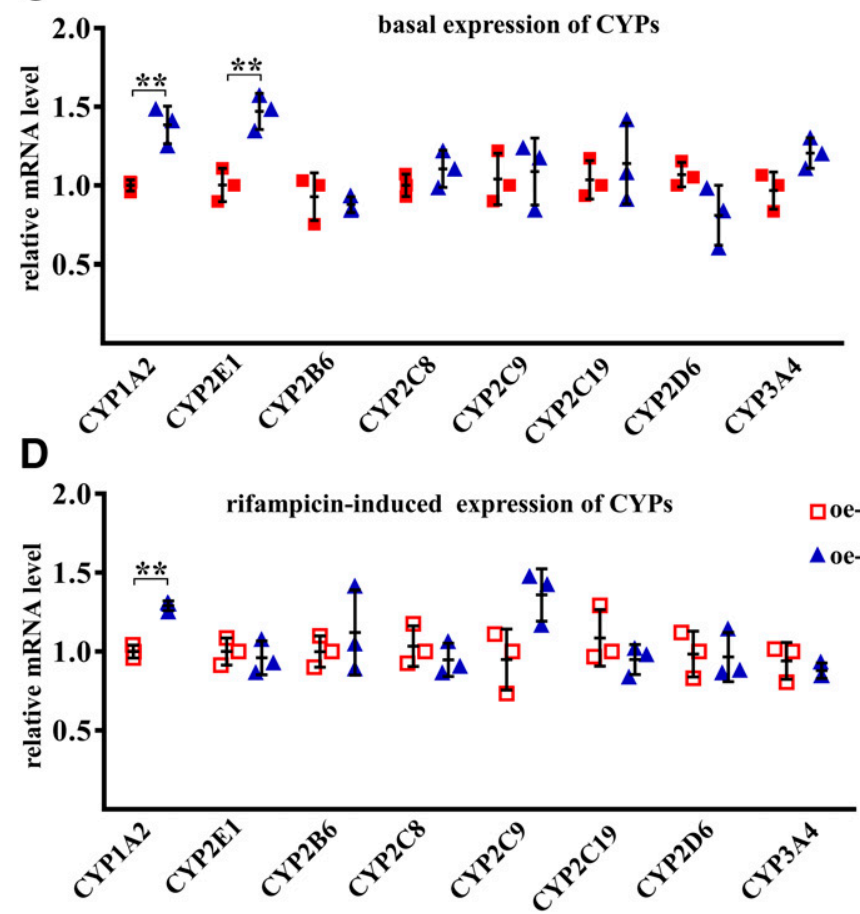

口oe-control+RIF

oe-HNF1 $\alpha$-AS1+RIF

Fig. 7. Effects of HNF $1 \alpha$-AS1 overexpression on mRNA levels of the studies genes. (A) Expression levels of HNF1 $\alpha$ AS1 in control and HNF1 $\alpha$-AS1-overexpressing (oe) Huh7 cells. (B) Impact of HNF $1 \alpha$-AS1 overexpression on the expression of $H N F 1 A, A H R, C A R$, and PXR mRNAs. (C) Impact of HNF1 $\alpha$-AS1 overexpression on the basal expression of $P 450$ mRNAs. (D) Impact of HNF1 $\alpha$-AS1 overexpression on the rifampicin-induced expression of $P 450 \mathrm{mRNAs}$. Data points from three independent experiments are shown as dots along with the mean \pm S.D., ${ }^{*} P<0.05 ; * * P<0.01$ in comparison of HNF $1 \alpha$-AS1 overexpression with the control group by two-tailed unpaired Student's $t$ test.

(Liu et al., 2016) and may serve as a biomarker for cancer prognosis (Zhang et al., 2017). Mechanistically, HNF1 $\alpha$-AS1 may function as a competing endogenous RNA to repress miRNA-mediated post-transcriptional regulation in cancer progression (Fang et al., 2017). Transcriptional regulation of HNF $1 \alpha$-AS1 by HNF $1 \alpha$ has also been reported in hepatocellular carcinoma (Ding et al., 2018). HNF1 $\alpha$-AS1 was further shown to directly bind to the $\mathrm{C}$ terminus of Scr homology region 2 domain-containing phosphatase 1 and increase the phosphatase activity of this protein, which can reverse the malignancy of hepatocellular carcinoma (Ding et al., 2018).

Given that we have found that HNF $1 \alpha$ and lncRNA HNF $1 \alpha$ AS1 constitute a regulatory network involved in receptormediated regulation of $\mathrm{P} 450$ enzyme expression, it therefore appears, based on current reports, that HNF1 $\alpha$-AS1 acts at the core of this regulatory mechanism. Moreover, such studies have provided potential future directions to further illustrate the molecular mechanisms of HNF1 $\alpha$-AS1 in the involvement of the HNF $1 \alpha$-mediated regulatory function in liver cells. A clear understanding of these mechanisms from the perspective of regulatory networks is necessary to support the clinical application of epigenetic regulation of drug metabolism and to facilitate the discovery of novel targets and strategies for the development of new drugs. For example, future research may reveal that lncRNAs regulate the expression of $\mathrm{P} 450 \mathrm{~s}$ by acting as a bridge, although the detailed mechanisms have not been established and should be explored further.

In conclusion, this study demonstrates that lncRNA HNF $1 \alpha-$ $\mathrm{AS} 1$, an antisense RNA of $\mathrm{HNF} 1 \alpha$, is involved in the HNF1 $\alpha$ mediated regulation of the expression of $\mathrm{P} 450 \mathrm{~s}$ and nuclear receptors in human liver cells.

\section{Authorship Contributions}

Participated in research design: Yan, Zhong, Han, Zhang.

Conducted experiments: Y. Wang, Yan, J. Liu, S. Chen, G. Liu, Nie, P. Wang, Yang.

Performed data analysis: Y. Wang, Yan, L. Chen, Zhong, Zhang.

Wrote or contributed to the writing of the manuscript: Yan, Zhong, Zhang.

\section{References}

Aouabdi S, Gibson G, and Plant N (2006) Transcriptional regulation of the PXR gene: identification and characterization of a functional peroxisome proliferatoractivated receptor alpha binding site within the proximal promoter of PXR. Drug Metab Dispos 34:138-144.

Chen L, Bao Y, Piekos SC, Zhu K, Zhang L, and Zhong XB (2018) A transcriptional regulatory network containing nuclear receptors and long noncoding RNAs controls basal and drug-induced expression of cytochrome P450s in HepaRG cells. Mol Pharmacol 94:749-759.

Cheung C, Akiyama TE, Kudo G, and Gonzalez FJ (2003) Hepatic expression of cytochrome P450s in hepatocyte nuclear factor 1-alpha (HNF1alpha)-deficient mice. Biochem Pharmacol 66:2011-2020.

Chiang TS, Yang KC, Chiou LL, Huang GT, and Lee HS (2014) Enhancement of CYP3A4 activity in Hep G2 cells by lentiviral transfection of hepatocyte nuclear factor-1 alpha. PLoS One 9:e94885. 
Dang Y, Lan F, Ouyang X, Wang K, Lin Y, Yu Y, Wang L, Wang Y, and Huang Q (2015) Expression and clinical significance of long non-coding RNA HNF1A-AS1 in human gastric cancer. World J Surg Oncol 13:302.

Ding CH, Yin C, Chen SJ, Wen LZ, Ding K, Lei SJ, Liu JP, Wang J, Chen KX, Jiang HL, et al. (2018) The HNF1 $\alpha$-regulated lncRNA HNF1A-AS1 reverses the malignancy of hepatocellular carcinoma by enhancing the phosphatase activity of SHP-1. Mol Cancer 17:63.

Fang C, Qiu S, Sun F, Li W, Wang Z, Yue B, Wu X, and Yan D (2017) Long non-coding RNA HNF1A-AS1 mediated repression of miR-34a/SIRT1/p53 feedback loop promotes the metastatic progression of colon cancer by functioning as a competing endogenous RNA. Cancer Lett 410:50-62.

Goodwin B, Hodgson E, and Liddle C (1999) The orphan human pregnane X receptor mediates the transcriptional activation of CYP3A4 by rifampicin through a distal enhancer module. Mol Pharmacol 56:1329-1339.

GTEx Consortium (2013) The genotype-tissue expression (GTEx) project. Nat Genet 45:580-585.

He H, Nie YL, Li JF, Meng XG, Yang WH, Chen YL, Wang SJ, Ma X, Kan QC, and Zhang LR (2016) Developmental regulation of CYP3A4 and CYP3A7 in Chinese Han population. Drug Metab Pharmacokinet 31:433-444.

Herriges MJ, Swarr DT, Morley MP, Rathi KS, Peng T, Stewart KM, and Morrisey EE (2014) Long noncoding RNAs are spatially correlated with transcription factors and regulate lung development. Genes Dev 28:1363-1379.

Ingelman-Sundberg M, Sim SC, Gomez A, and Rodriguez-Antona C (2007) Influence of cytochrome P450 polymorphisms on drug therapies: pharmacogenetic, pharmacoepigenetic and clinical aspects. Pharmacol Ther 116:496-526.

Jover R, Bort R, Gómez-Lechón MJ, and Castell JV (2001) Cytochrome P450 regulation by hepatocyte nuclear factor 4 in human hepatocytes: a study using adenovirus-mediated antisense targeting. Hepatology 33:668-675.

Kamiyama Y, Matsubara T, Yoshinari K, Nagata K, Kamimura H, and Yamazoe Y (2007) Role of human hepatocyte nuclear factor 4alpha in the expression of drugmetabolizing enzymes and transporters in human hepatocytes assessed by use of small interfering RNA. Drug Metab Pharmacokinet 22:287-298.

Kaneko S, Bonasio R, Saldaña-Meyer R, Yoshida T, Son J, Nishino K, Umezawa A and Reinberg D (2014) Interactions between JARID2 and noncoding RNAs regulate PRC2 recruitment to chromatin. Mol Cell 53:290-300.

Khorkova O, Hsiao J, and Wahlestedt C (2015) Basic biology and therapeutic implications of lncRNA. Adv Drug Deliv Rev 87:15-24.

Kung JT, Colognori D, and Lee JT (2013) Long noncoding RNAs: past, present, and future. Genetics 193:651-669.

$\mathrm{Li} \mathrm{T}$ and Chiang JY (2006) Rifampicin induction of CYP3A4 requires pregnane X receptor cross talk with hepatocyte nuclear factor 4alpha and coactivators, and suppression of small heterodimer partner gene expression. Drug Metab Dispos 34:756-764.

Liu SY and Gonzalez FJ (1995) Role of the liver-enriched transcription factor HNF-1 alpha in expression of the CYP2E1 gene. DNA Cell Biol 14:285-293.

Liu Z, Wei X, Zhang A, Li C, Bai J, and Dong J (2016) Long non-coding RNA HNF1A-AS1 functioned as an oncogene and autophagy promoter in hepatocellular carcinoma through sponging hsa-miR-30b-5p. Biochem Biophys Res Commun 473:1268-1275.

Ma L, Bajic VB, and Zhang Z (2013) On the classification of long non-coding RNAs. RNA Biol 10:925-933.

Müller S, Raulefs S, Bruns P, Afonso-Grunz F, Plötner A, Thermann R, Jäger C, Schlitter AM, Kong B, Regel I, et al. (2015) Next-generation sequencing reveals novel differentially regulated mRNAs, lncRNAs, miRNAs, sdRNAs and a piRNA in pancreatic cancer. Mol Cancer 14:94.

Nair PC, McKinnon RA, and Miners JO (2016) Cytochrome P450 structure-function: insights from molecular dynamics simulations. Drug Metab Rev 48:434-452.

Nie YL, He H, Li JF, Meng XG, Yan L, Wang P, Wang SJ, Bi HZ, Zhang LR, and Kan QC (2017) Hepatic expression of transcription factors affecting developmental regulation of UGT1A1 in the Han Chinese population. Eur J Clin Pharmacol 73:29-37.

Pan YZ, Gao W, and Yu AM (2009) MicroRNAs regulate CYP3A4 expression via direct and indirect targeting. Drug Metab Dispos 37:2112-2117.

Peng L and Zhong X (2015) Epigenetic regulation of drug metabolism and transport. Acta Pharm Sin B 5:106-112.
Pinto N and Dolan ME (2011) Clinically relevant genetic variations in drug metabolizing enzymes. Curr Drug Metab 12:487-497.

Tang X and Chen S (2015) Epigenetic regulation of cytochrome P450 enzymes and clinical implication. Curr Drug Metab 16:86-96.

Tirona RG, Lee W, Leake BF, Lan LB, Cline CB, Lamba V, Parviz F, Duncan SA, Inoue Y, Gonzalez FJ, et al. (2003) The orphan nuclear receptor HNF4alpha determines PXR- and CAR-mediated xenobiotic induction of CYP3A4. Nat Med 9:220-224.

Tompkins LM and Wallace $\mathrm{AD}$ (2007) Mechanisms of cytochrome P450 induction. $J$ Biochem Mol Toxicol 21:176-181.

Tracy TS, Chaudhry AS, Prasad B, Thummel KE, Schuetz EG, Zhong XB, Tien YC, Jeong H, Pan X, Shireman LM, et al. (2016) Interindividual variability in cytochrome P450-mediated drug metabolism. Drug Metab Dispos 44:343-351.

Tsuchiya Y, Nakajima M, Takagi S, Taniya T, and Yokoi T (2006) MicroRNA regulates the expression of human cytochrome P450 1B1. Cancer Res 66:9090-9098.

Uno Y, Sakamoto Y, Yoshida K, Hasegawa T, Hasegawa Y, Koshino T, and Inoue I (2003) Characterization of six base pair deletion in the putative HNF1-binding site of human PXR promoter. J Hum Genet 48:594-597.

Villegas VE and Zaphiropoulos PG (2015) Neighboring gene regulation by antisense long non-coding RNAs. Int J Mol Sci 16:3251-3266.

Wang KC, Yang YW, Liu B, Sanyal A, Corces-Zimmerman R, Chen Y, Lajoie BR, Protacio A, Flynn RA, Gupta RA, et al. (2011) A long noncoding RNA maintains active chromatin to coordinate homeotic gene expression. Nature 472:120-124.

Waxman DJ (1999) P450 gene induction by structurally diverse xenochemicals: central role of nuclear receptors CAR, PXR, and PPAR. Arch Biochem Biophys 369:11-23.

Yan L, Wang Y, Liu J, Nie Y, Zhong XB, Kan Q, and Zhang L (2017) Alterations of histone modifications contribute to pregnane $\mathrm{X}$ receptor-mediated induction of CYP3A4 by rifampicin. Mol Pharmacol 92:113-123.

Yang X, Song JH, Cheng Y, Wu W, Bhagat T, Yu Y, Abraham JM, Ibrahim S, Ravich W, Roland BC, et al. (2014) Long non-coding RNA HNF1A-AS1 regulates proliferation and migration in oesophageal adenocarcinoma cells. Gut 63:881-890.

Yu AM, Ingelman-Sundberg M, Cherrington NJ, Aleksunes LM, Zanger UM, Xie W, Jeong H, Morgan ET, Turnbaugh PJ, Klaassen CD, et al. (2017) Regulation of drug metabolism and toxicity by multiple factors of genetics, epigenetics, lncRNAs, gut microbiota, and diseases: a meeting report of the $21^{\text {st }}$ International Symposium on Microsomes and Drug Oxidations (MDO). Acta Pharm Sin B 7:241-248.

Yu AM, Tian Y, Tu MJ, Ho PY, and Jilek JL (2016) MicroRNA pharmacoepigenetics: posttranscriptional regulation mechanisms behind variable drug disposition and strategy to develop more effective therapy. Drug Metab Dispos 44:308-319.

Zanger UM, Klein K, Thomas M, Rieger JK, Tremmel R, Kandel BA, Klein M, and Magdy T (2014) Genetics, epigenetics, and regulation of drug-metabolizing cytochrome p450 enzymes. Clin Pharmacol Ther 95:258-261.

Zanger UM and Schwab M (2013) Cytochrome P450 enzymes in drug metabolism: regulation of gene expression, enzyme activities, and impact of genetic variation. Pharmacol Ther 138:103-141.

Zhang X, Xiong Y, Tang F, Bian Y, Chen Y, and Zhang F (2017) Long noncoding RNA HNF1A-AS1 indicates a poor prognosis of colorectal cancer and promotes carcinogenesis via activation of the Wnt/B-catenin signaling pathway. Biomed Pharmacother 96:877-883.

Zhou L, Sun K, Zhao Y, Zhang S, Wang X, Li Y, Lu L, Chen X, Chen F, Bao X, et al. (2015) Linc-YY1 promotes myogenic differentiation and muscle regeneration through an interaction with the transcription factor YY1. Nat Commun 6:10026.

Zhou SF, Liu JP, and Chowbay B (2009) Polymorphism of human cytochrome P450 enzymes and its clinical impact. Drug Metab Rev 41:89-295.

Address correspondence to: Dr. Lirong Zhang, Department of Pharmacology, School of Basic Medical Sciences, Zhengzhou University, Zhengzhou, Henan, China. E-mail: zhanglirongzzu@126.com Dr. Shengna Han, Department of Pharmacology, School of Basic Medical Sciences, Zhengzhou University, Zhengzhou, Henan, China. E-mail: hanshengna@126.com 